\title{
Colonoscopy for colorectal cancer screening-is it effective in the hands of a general surgery resident?
}

\author{
Maciej Matyja' ${ }^{1}$ Artur Pasternak², Michał Wysocki', Michał Pędziwiatr', Mirosław Szura ${ }^{3}$, Kazimierz Rembiasz' \\ '2nd Department of Ceneral Surgery, Jagiellonian University Medical College, Cracow, Poland \\ 2Department of Anatomy, Jagiellonian University Medical College, Cracow, Poland \\ BDepartment of Experimental and Clinical Surgery, Jagiellonian University Medical College, Cracow, Poland
}

Article history: Received: 31.05.2018 Accepted: 31.04.2018 Published: 31.10.2018

ABSTRACT: $\quad$ INTRODUCTION: Colonoscopy is considered to be a gold standard for colorectal cancer (CRC) screening. Endoscopy training is an essential component of general surgery training program. Patients should receive care at the highest level possible, nevertheless residents need to gain experience. The aim of our study was to evaluate the effectiveness of colonoscopy performed by general surgery residents by comparing quality indicators between surgical trainees and consultants.

MATERIALS AND METHODS: The analysis included 6384 patients aged 40-65 who underwent screening colonoscopy between October 2014 and February 2018. The patients were divided into two groups: group I-patients examined by residents, group II - patients examined by board-certified general surgeons. Quality indicators such as cecal intubation rate, adenoma detection rate and patient tolerance scale were compared between the two groups.

RESULTS: Croup I comprised 2268 (35.53\%) and group II 4116 (64.47\%) patients. The overall cecal intubation rate (CIR) was $95.99 \%$, equal for both groups $(p=0.994)$. There was no statistically significant difference in adenoma detection rate: $29.30 \%$ among residents and $27.66 \%$ among consultants $(p=0.203)$. Patient tolerance of the examination was very good (4-point scale) in consultants group in $78.98 \%$ of cases and in $75.18 \%$ cases among residents $(p<0.001)$.

CONCLUSION: In a proper learning environment general surgery residents are able to perform high-quality and effective screening colonoscopy. However, residents need to continue the progress in their technique to improve patient tolerance in order to reach the proficiency of a consultant.

KEYWORDS: $\quad$ colorectal, cancer, screening, colonoscopy, residents, quality

\section{INTRODUCTION}

Colorectal cancer (CRC) is one of the leading causes of mortality and morbidity worldwide. It is the second most common cancer in Europe and the second most common cause of cancer-related deaths. CRC develops from precancerous polyps in the colon or rectum and is both preventable and treatable when diagnosed early and with the removal of premalignant polyps. Colonoscopy plays a critical role in early detection and removal of precancerous lesions and it has been considered to be the gold standard tool of screening with a high sensitivity and specificity $[1,2,3]$.

Measurable quality indicators/parameters for endoscopy have been selected and formulated. Complete colonoscopy, which is defined by passage of the colonoscope along the whole length of the colon to the cecum or terminal ileum is one of the crucial measures of the procedure quality. It is expressed by cecal intubation rate (CIR) [4]. CIR is not only a quality indicator but it also delivers the information about the skills of a physician performing examinations. Minimum standard cecal intubation rate should exceed $90 \%$ according to the American Society for Gastrointestinal Endoscopy (ASGE) and the American College of Gastroenterology (ACG) [5].

Another essential indicator of quality is adenoma detection rate (ADR), i.e. the percent of patients aged $\geq 50$ years undergoing first-time screening colonoscopy who have one or more conventional adenomas detected and removed. European Society of Gastrointestinal Endoscopy (ESGE) recommendations state that an experienced colonoscopist should achieve ADR of at least $25 \%[6,7]$. A high $\mathrm{ADR}$ is associated with decreased interval colorectal cancer rate.
Endoscopy training is an essential component of general surgery training program. Current recommendations of screening programs define a minimum lifetime experience of screening colonoscopists and a minimum number of screening examinations. A minimum lifetime experience of 1000 colonoscopies and a minimum annual number of 150 screening colonoscopies are recommended as sufficient for a physician to take part in CRC screening $[8,9]$.

In an attempt to further standardize surgical training, the Polish Board of Surgery now requires that residents provide evidence that they are certified in flexible endoscopy. This prospective study aimed to determine whether, through a structured curriculum, junior level residents could conduct a competent and safe screening colonoscopy. The aim of our study was to evaluate the quality and the effectiveness of colonoscopy performed by general surgery residents by comparing quality indicators between surgical trainees and consultants performing CRC screening.

\section{MATERIALS AND METHODS}

We conducted a dual-center study in the 2nd Department of Surgery, Jagiellonian University Medical College and the Specialist Diagnostic and Therapeutic Center "Medicina" in Cracow, Poland. The study was approved by the local ethics committee and conducted in accordance with the principles of the Declaration of Helsinki (KBN no 122.6120.36.2016).

\section{Patients}

We selected 6384 patients aged 40-65 years who underwent colo- 
noscopy screening between October 2014 and February 2018 (as a part of a national colorectal cancer-screening program, which was financed by the Polish Ministry of Health). Patients with a history of inflammatory bowel disease, active malignancy, or a high anesthetic risk (ASA IV) were excluded from the study. All patients were pre-evaluated before the examination and a written informed consent for the procedure was obtained. Patients were informed to take a liquid propulsive agent (i.e. $420 \mathrm{~g}$ of polyethylene glycol [PEG] in 4 $\mathrm{L}$ of water) in the evening prior to the procedure for morning patients and in a split-dose regimen for those in the afternoon schedule.

\section{Setting}

We used Olympus series colonoscopes (Olympus Optical Co. Ltd, Tokyo, Japan). Patients were sorted into two groups according to the experience of the physician performing the colonoscopy.

Group I included 2268 patients examined by surgical trainees i.e. general surgery residents, that have already obtained Endoscopic Skills Certificate from the Society of Polish Surgeons. Group II included 4116 patients examined by board-certified general surgeons (each of whom has performed more than 5000 colonoscopies).

Patients' preoperative characteristics including demographics, body mass index (BMI), family history of malignancy and significant comorbidities were determined.

\section{Outcome}

ADR was determined as a number of colonoscopies during which one or more histologically confirmed adenomas were found divided by the total number of colonoscopies performed. We compared ADR between the two groups of patients.

Cecal intubation was defined as deep intubation into the cecum with the tip of the endoscope being able to touch the appendiceal orifice. Cecal intubation rate was another quality indicator that we assessed between the two groups. Another endpoints of the study that potentially differ between two groups were analyzed: patient tolerance of examination (4-point scale), location of lesions

\section{STATISTICAL ANALYSIS}

All data were analyzed with Statsoft STATISTICA v.12.5 (Statsoft Inc, Tulsa, Oklahoma, USA). The results are presented as mean \pm standard deviation (SD), median and interquartile range (IQR), when appropriate. The study of categorical variables used the Pearson's chi-square test, chi-square with Yates correction when appropriate. The Shapiro-Wilk test was used to check for normal distribution of data. Quantitative data were analyzed with Student's t-test (for normally distributed data) and Mann-Whitney's (for non-normally distributed data). Univariate and multivariate logistic regression models were built including continuous and categorical variables. Results were considered statistically significant when the p-value was found to be less than 0.05 .

\section{RESULTS}

We observed no difference between the groups regarding sex and
BMI ( $\mathrm{p}=0.089$ and 0.607 , respectively). There was a slight difference in median age between the two groups: 62 vs. 63, respectively $(\mathrm{p}<0.001)$. Family history of malignancy was not different $(8.73 \%$ vs. $8.60 \%, \mathrm{p}=0.860)$.

Basic characteristics and comparison between group I and group II including past medical history are presented in Table I.

The overall cecal intubation rate (CIR) was $95.99 \%$, equal for both groups ( $\mathrm{p}=0.994)$. There was no statistically significant difference in another quality indicator, i.e. adenoma detection rate. Complete ADR was $28.23 \%, 29.3 \%$ in residents group and $27.66 \%$ among consultants $(\mathrm{p}=0.203)$. The results are presented in Table II.

Location of changes is presented in Table III.

Table IV presents univariate and multivariate logistic regression analysis of influence of selected factors on cecal intubation rate. Significant factors were patients' sex, tolerance of examination and bowel preparation.

Table V presents univariate and multivariate logistic regression analysis of influence of selected factors on adenoma detection rate. Significant factors were: cecal intubation rate, patients' sex, tolerance of examination and bowel preparation.

\section{DISCUSSION}

Endoscopy training has been one of the essential components of general surgery residency program in Poland. It is also required by the Association of Polish Surgeons (AJS). The importance of endoscopic training during residency has been well documented by graduates and program directors $[10,11]$.

Recently, in 2014 the Polish Ministry of Health accepted new general surgery residency program, with increased up to 100 gastrointestinal endoscopies required for graduating residents to perform. However, the AJS has more strict requirements for board certification. In order to get the AJS accreditation, the candidates have to perform at least 100 colonoscopies and 50 polypectomies. To perform colorectal cancer screening colonoscopy, a physician needs to have either the above mentioned certification or graduation from general surgery or gastroenterology, alternatively. Currently, the international endoscopic societies tend to resign from arbitrary numbers and state that competency level should be based on more objective criteria [12].

It has been already demonstrated that surgeons can perform high-quality endoscopy with low rates of complications. Reports, including prospective studies, confirm that colonoscopies performed by surgeons are at the highest quality, with the results comparable to those done by gastroenterologists [13, 14]. According to our knowledge, there are only a few studies comparing outcomes in endoscopy between residents and consultants. We have not found any reports concerning particularly CRC screening colonoscopy and differences in performance between those two groups of physicians.

At both institutions where our study took place, residents with adequate experience, after the acceptance of the head of the department, performed examinations without a direct supervision. 
Tab. I. Basic group characteristics.

\begin{tabular}{|c|c|c|c|c|}
\hline & ALL & RESIDENTS & CONSULTANTS & P-VALUE \\
\hline $\mathrm{N}(\%)$ & $6384(100 \%)$ & $2268(35.53 \%)$ & $4116(64.47 \%)$ & - \\
\hline Males/Females (\%) & $3154 / 3230(49 \% / 51 \%)$ & $1153 / 1115(51 \% / 49 \%)$ & $2001 / 2115(49 \% / 51 \%)$ & $0.089^{1}$ \\
\hline Median age (IQR) & $62(60-64)$ & $62(59-64)$ & $63(60-65)$ & $<0.001^{2}$ \\
\hline Median BMI (IQR) & $27.55(24.91-30.49)$ & $27.68(25.07-30.80)$ & $27.47(24.85-30.48)$ & $0.067^{2}$ \\
\hline Malignancy history & $552(8.65 \%)$ & $198(8.73 \%)$ & $354(8.6 \%)$ & $0.86^{1}$ \\
\hline Previous colonoscopy & $1013(15.87 \%)$ & $415(18.3 \%)$ & $598(14.53 \%)$ & $<0.001^{1}$ \\
\hline Lower gastrointestinal tract bleeding/Anemia & $91(1.43 \%)$ & $65(2.87 \%)$ & $26(0.63 \%)$ & $<0.001^{1}$ \\
\hline Nonintentional weight loss & $19(0.3 \%)$ & $16(0.71 \%)$ & $3(0.07 \%)$ & $<0.001^{1}$ \\
\hline Changes in bowel movement routine & $47(0.74 \%)$ & $32(1.41 \%)$ & $15(0.36 \%)$ & $<0.001^{1}$ \\
\hline Medications & $1112(17.42 \%)$ & $438(19.31 \%)$ & $674(16.38 \%)$ & $0.003^{1}$ \\
\hline Aspirin & $983(15.4 \%)$ & $389(17.15 \%)$ & $594(14.43 \%)$ & $0.004^{1}$ \\
\hline Sintrom/Acenokumarol/Warfin & $72(1.13 \%)$ & $29(1.28 \%)$ & $43(1.04 \%)$ & $0.469^{3}$ \\
\hline Plavix/Clopidogrel/Areplex/Trombex/Plavocorin & $43(0.67 \%)$ & $30(0.73 \%)$ & $13(0.57 \%)$ & $0.57^{3}$ \\
\hline Smoking & $1181(18.5 \%)$ & $396(17.46 \%)$ & $785(19.07 \%)$ & $0.112^{1}$ \\
\hline Operations & $2691(42.15 \%)$ & 949 (41.84\%) & $1742(42.32 \%)$ & $0.71^{1}$ \\
\hline Cardiovascular comorbidity & $660(10.34 \%)$ & $246(10.85 \%)$ & $414(10.06 \%)$ & $0.322^{1}$ \\
\hline Pulmonary comorbidity & $241(3.78 \%)$ & $88(3.88 \%)$ & $153(3.72 \%)$ & $0.743^{1}$ \\
\hline $\mathrm{DM}_{2}$ & $700(10.96 \%)$ & $224(9.88 \%)$ & $476(11.56 \%)$ & $0.039^{1}$ \\
\hline Chronic kidney disease & $33(0.52 \%)$ & $15(0.66 \%)$ & $18(0.44 \%)$ & $0.311^{3}$ \\
\hline
\end{tabular}

${ }^{1}$ chi-square Pearson's test

${ }^{2}$ Mann-Whitney's test

${ }^{3}$ chi-square with Yates correction

A board-certified surgeon, who is a supervisor, was present in the endoscopy department and was always willing to assist when needed. This sort of solution gives a resident a chance to make autonomic decisions, but at the same time a possibility to use the knowledge of a more experienced colleague. We have not noticed any inconvenience concerning our work system so far. When there is an indication to stop the examination before reaching the cecum (i.e. severe pain or potential risk of perforation) trainees do not force the colonoscopy. The patients are referred for CT scan, CT colonoscopy or barium enema, when required. To keep the highest possible quality level we follow the rule of a minimum 6 minutes of withdrawal time that has been recently reported and is considered as a standard because of its correlation with ADR $[15,16]$.

Our study has shown that there are statistically significant differences concerning patients' tolerance between the two groups. Colonoscopies performed under local anesthesia by residents were not tolerated as well as the ones performed by the consultants. As many as $75.18 \%$ of examinations were rated as very good in a matter of tolerance vs. $78.98 \%$ performed by consultants. There are reports stating that patients undergoing colonoscopy performed by surgeons are more likely to report pain than patients examined by gastroenterologists [17]. But we have not found any paper distinguishing pain reports between the residents and consultants. Higher discomfort may have influence on completion rates. Evaluating patient's tolerance is also questionable. The physician's and patient's opinion may vary in terms of the comfort level during the procedure. In our paper we analyzed results reported by the physicians.

Our study showed that the results of CRC screening colonoscopy and its quality are comparable for residents and consultant specia- lists. Slightly lower patient's tolerance of the examinations performed by trainees did not affect the completion rates. There was no statistically significant difference in cecal intubation rate between the groups: $95.99 \%$ among residents and $95.99 \%$ among consultants. CIR outcomes in both groups meet the recommendations of the European Commission and National Health Service Bowel Cancer Screening Programme in England (NHSBCSP), where 90\% CIR is a minimum [18]. Residents and board-certified surgeons at our institution also meet stricter requirements of the US Multi-Society Task Force on Colorectal Cancer, where a benchmark for screening population is set at 95\% [19].

The ADR between the two study groups showed no statistically significant difference. It exceeds the minimum standards described in the literature, such as the American Society for Gastrointestinal Endoscopy (ASGE) recommendations, which state that adenomas should be detected in more than $25 \%$ of the asymptomatic male patients and in more than $15 \%$ of the females [20]. ADR calculated as described in the methods section was $28.23 \%$ in total, and did not show any significant differences in the chi-square test or univariate logistic regression. ADR of residents was $29.30 \%$ and of consultants $27.66 \%$ (p-values respectively 0.203 and 0.199 ). There is a possibility that this $1.64 \%$ difference between ADRs resulted from the fact that the consultants have more experience with narrow band imaging (NBI), which enhances micro-vessel architecture and determines the decision not to remove hyperplastic polyps [21]. However, not every report contained Kudo classification describing the detected lesion, so it is hard to determine what was the real influence of NBI on ADR.

To sum up, in our study the residents did not differ from the consul- 
Tab. II. Results of colonoscopies performed as a part of a screening program for early detection of colorectal cancer.

\begin{tabular}{|c|c|c|c|c|}
\hline & ALL & RESIDENTS & CONSULTANTS & P-VALUE \\
\hline Cecal intubation rate & $6128(95.99 \%)$ & $2177(95.99 \%)$ & $3951(95.99 \%)$ & $0.994^{1}$ \\
\hline ADR & $1516(28.23 \%)$ & $543(29.3 \%)$ & $973(27.66 \%)$ & $0.203^{1}$ \\
\hline General anesthesia & $616(9.65 \%)$ & $201(8.86 \%)$ & $415(10.08 \%)$ & $0.114^{1}$ \\
\hline Tolerance of exam (local anesthesia) & & & & $<0.001^{1}$ \\
\hline poor & $180(2.82 \%)$ & $87(3.84 \%)$ & $93(2.26 \%)$ & \\
\hline medium & $336(5.26 \%)$ & $148(6.53 \%)$ & $188(4.57 \%)$ & \\
\hline good & $912(14.29 \%)$ & $328(14.46 \%)$ & $584(14.19 \%)$ & \\
\hline very good & $4956(77.63 \%)$ & $1705(75.18 \%)$ & $3251(78.98 \%)$ & \\
\hline
\end{tabular}

${ }^{1}$ chi-square Pearson's test

Tab. III. Location of changes.

\begin{tabular}{llll} 
& ALL & RESIDENTS & CONSULTANTS \\
\hline Caecum & $120(1.88 \%)$ & $57(2.51 \%)$ & $63(1.53 \%)$ \\
\hline Ascending colon and hepatic flexure & $247(3.87 \%)$ & $106(4.67 \%)$ & $141(3.43 \%)$ \\
\hline Transverse colon & $149(2.33 \%)$ & $54(2.38 \%)$ & $95(2.31 \%)$ \\
\hline Splenic flexure and descending colon & $142(2.22 \%)$ & $59(2.6 \%)$ & $95(2.31 \%)$ \\
\hline Sigmoideum & $1046(16.38 \%)$ & $715(31.53 \%)$ & $331(8.04 \%)$ \\
Rectum & $672(10.53 \%)$ & $513(22.62 \%)$ & $159(3.86 \%)$
\end{tabular}

${ }^{1}$ chi-square Pearson's test

Tab. IV. Univariate and multivariate logistic regression model of factor potentially influencing cecal intubation rate.

\begin{tabular}{|c|c|c|c|}
\hline & OR & $95 \% \mathrm{Cl}$ & P-VALUE \\
\hline \multicolumn{4}{|l|}{ UNIVARIATE } \\
\hline Residents vs. specialists & 1 & $0.99-1.01$ & 0.823 \\
\hline Males/Females & 1.84 & $1.42-2.4$ & $<0.001$ \\
\hline Age & 1 & $0.98-1.02$ & 0.855 \\
\hline Obesity & 1.23 & $0.93-1.64$ & 0.152 \\
\hline Previous colonoscopy & 0.86 & $0.62-1.18$ & 0.347 \\
\hline LGI Bleeding/Anemia & 1.87 & $0.46-7.64$ & 0.383 \\
\hline Nonintentional weight loss & 1.91 & $0.001-11.53$ & 0.734 \\
\hline Changes in bowel movement routine & 1.34 & $0.001-173.57$ & 0.91 \\
\hline Medications & 1.05 & $0.74-1.48$ & 0.796 \\
\hline Aspirin & 1.05 & $0.75-1.46$ & 0.791 \\
\hline Anesthesia & 2.44 & $1.33-4.49$ & 0.004 \\
\hline Tolerance of exam & 4.97 & $4.37-5.66$ & $<0.001$ \\
\hline Bowel preparation $\mathrm{R}$ & 1.08 & $1.07-1.08$ & $<0.001$ \\
\hline Bowel preparation $\mathrm{M}$ & 1.07 & $1.06-1.08$ & $<0.001$ \\
\hline Bowel preparation L & 1.07 & $1.04-1.09$ & $<0.001$ \\
\hline \multicolumn{4}{|l|}{ MULTIVARIATE } \\
\hline Males/Females & 1.2 & $0.74-1.93$ & 0.463 \\
\hline Anesthesia & 1.79 & $0.65-4.98$ & 0.262 \\
\hline Tolerance of exam & 2.12 & $1.65-2.72$ & $<0.001$ \\
\hline Bowel preparation $\mathrm{R}$ & 1.07 & $1.05-1.08$ & $<0.001$ \\
\hline Bowel preparation $M$ & 1 & $0.99-1.02$ & 0.602 \\
\hline Bowel preparation L & 1.08 & $1.03-1.13$ & $<0.001$ \\
\hline
\end{tabular}

tant surgeons in terms of quality of screening colonoscopy. The factors describing CRC screening have been maintained at the highest level. Of course, it is unquestionable that residents require proper training methods before having a possibility to become independent from their supervisors. Our training methods as described above are accepted internationally and similar studies have confirmed their successfulness [22, 23]. At the same time, patients undergoing screening colonoscopy are provided with the best possible medical care. Resi- 
Tab. V. Univariate and mulitivariate logistic regression model of factor potentially influencing ADR.

\begin{tabular}{|c|c|c|c|}
\hline & OR & $95 \% \mathrm{Cl}$ & P-VALUE \\
\hline \multicolumn{4}{|l|}{ UNIVARIATE } \\
\hline Residents vs. specialists & 0.92 & $0.82-1.04$ & 0.199 \\
\hline Males/Females & 0.5 & $0.45-0.57$ & $<0.001$ \\
\hline Age & 1.03 & $1.01-1.05$ & 0.003 \\
\hline Obesity & 1.28 & $1.12-1.45$ & $<0.001$ \\
\hline LGI Bleeding/Anemia & 1.14 & $0.68-1.91$ & 0.625 \\
\hline Nonintentional weight loss & 1.13 & $0.35-3.69$ & 0.839 \\
\hline Changes in bowel movement routine & 1.17 & $0.57-2.38$ & 0.672 \\
\hline Medications & 1.04 & $0.9-1.21$ & 0.561 \\
\hline Aspirin & 1.02 & $0.74-1.39$ & 0.92 \\
\hline Anesthesia & 1.2 & $0.98-1.47$ & 0.083 \\
\hline Tolerance of exam & 1.38 & $1.25-1.52$ & $<0.001$ \\
\hline Cecal intubation rate & 3.48 & $2.23-5.44$ & $<0.001$ \\
\hline Bowel preparation $\mathrm{R}$ & 1.02 & $1.01-1.02$ & $<0.001$ \\
\hline Bowel preparation M & 1.01 & $1.01-1.02$ & $<0.001$ \\
\hline Bowel preparation L & 0.99 & $0.98-1.01$ & 0.444 \\
\hline \multicolumn{4}{|l|}{ MULTIVARIATE } \\
\hline Males/Females & 0.53 & $0.47-0.6$ & $<0.001$ \\
\hline Age & 1.03 & $1.01-1.43$ & $<0.001$ \\
\hline Obesity & 1.23 & $1.08-1.4$ & 0.002 \\
\hline Tolerance of exam & 1.17 & $1.05-1.3$ & 0.006 \\
\hline Cecal intubation rate & 1.67 & $0.87-3.23$ & 0.122 \\
\hline Bowel preparation $\mathrm{R}$ & 1.01 & $1-1.03$ & 0.018 \\
\hline Bowel preparation M & 1.01 & $1-1.02$ & 0.131 \\
\hline
\end{tabular}

dents before performing independent examinations need a proper education provided by our consultant, but as soon as physicians enter CRC screening program, their results are monitored. The Polish Ministry of Health keeps auditing the quality of CRC screening, so it is impossible to lower the desired standards in the accredited institutions. There are several limitations to our study. It was limited to two departments, where physicians performing examinations work in university centers having accreditations to issue certificates of competency in endoscopy. For a better perspective, more data from non-academic centers are required. However, our study described a large number of screening endoscopic examinations. Our results

\section{REFERENCES:}

1. Siegel R.L., Miller K.D., Jemal A.: Cancer statistics, 2015. CA: A Cancer Journal for Clinicians 2015; 65: 5-29.

2. Ferlay J., Soerjomataram I.I., Dikshit R., Eser S., Mathers C., Rebelo M. et al.: Cancer incidence and mortality worldwide: sources, methods and major patterns in GLOBOCAN 2012. Int J Cancer. 2014; 136: E359-386.

3. Dziki Ł., Puła A., Stawiski K., Mudza B., Włodarczyk M., Dziki A.: Patients' awareness of the prevention and treatment of colorectal cancer. Pol Przegl Chir. 2015 Sep; 87 (9): 459-463.

4. Rex D.K., Bond J.H., Winawer S. et al.: Quality in the technical performance of colonoscopy and the continuous quality improvement process for colonoscopy: recommendations of the U.S. Multi-Society Task Force on Colorectal Cancer. Am J Gastroenterol. 2002; 97 (6): 1296-1308.

5. Marshall J.B., Barthel J.S.: The frequency of total colonoscopy and terminal ileal intubation in the 1990s. Gastrointest Endosc. 1993; 39 (4): 518-520.

6. Regula J., Rupinski M., Kraszewska E. et al.: Colonoscopy in colorectal-cancer may become a foundation to improve the quality and training of general surgery residents.

\section{CONCLUSION}

Within a proper learning environment general surgery residents are able to perform high-quality and effective screening colonoscopy. Examinations carried out by residents have the same value as the ones performed by board-certified surgeons. However, there is a room for improvement in patient's tolerance in order to reach the proficiency of a consultant.

screening for detection of advanced neoplasia. N Engl J Med. 2006; 355: 1863-1872.

7. Gonçalves A.R., Ferreira C., Marques A. et al.: Assessment of quality in screening colonoscopy for colorectal cancer. Clin Exp Gastroenterol. 2011; 4: 277-281.

8. Barton R.: Validity and reliability of an accreditation assessment for colonoscopy. Gut 2008; 57: A4.

9. Rabeneck L., Paszat L.F., Hilsden R.J. et al.: Bleeding and perforation after outpatient colonoscopy and their risk factors in usual clinical practice. Gastroenterology. 2008; 135: 1899-1906.

10. Unger S.W., Satava R.M., Scott J.S.: Resident education in surgical endoscopy. Am Surg. 1992; 58: 643-646.

11. Morales M.P., Mancini G.J., Miedema B.W., Rangnekar N.J., Koivunen D.G., Ramshaw B.J., Eubanks W.S., Stephenson H.E.: Integrated flexible endoscopy training during surgical residency. Surg Endosc. 2008; 22 (9): 2013-2017.

12. Hope W.W., Hooks W.B. 3rd, Kilbourne S.N., Adams A., Kotwall C.A., Clancy T.V.: Assessing resident performance and training of colonoscopy in a general 
surgery training program. Surg Endosc. 2013 May; 27 (5): 1706-1710.

13. Wexner S.D., Forde K.A., Sellers G., Geron N., Lopes A., Weiss E.G., Nogueras J.J.: How well can surgeons perform colonoscopy? Surg Endosc. 1998; 12: 1410-1414.

14. Wexner S.D., Garbus J.E., Singh J.J.: A prospective analysis of 13,580 colonoscopies. Reevaluation of credentialing guidelines. Surg Endosc. 2001; 15: 251-261.

15. Barclay R.L., Vicari J.J., Doughty A.S. et al.: Colonoscopic withdrawal times and adenoma detection during screening colonoscopy. N Engl J Med. 2006; 355: 2533-2541.

16. Simmons D.T., Harewood G.C., Baron T.H. et al.: Impact of endoscopist withdrawal speed on polyp yield: implications for optimal colonoscopy withdrawal time. Aliment Pharmacol Ther. 2006; 24: 965-971.

17. Seip B., Bretthauer M., Dahler S. et al.: Patient satisfaction with on-demand sedation for outpatient colonoscopy. Endoscopy. 2010; 42: 639-646.

18. Rutter M.D., Chilton A.: Quality assurance guidelines for colonoscopy. NHS BCSP Publication. 2011; 6: 24.
19. Rex D.K., Imperiale T.F., Portish V.: Patients willing to try colonoscopy without sedation: associated clinical factors and results of a randomized controlled trial. Gastrointest Endosc. 1999; 49: 554-559.

20. Diamond S.J., Enestvedt B.K., Jiang Z. et al.: Adenoma detection rate increases with each decade of life after 50 years of age. Gastrointest Endosc. 2011 Jul; 74 (1): 135-140.

21. Inoue T., Murano M., Murano N. et al.: Comparative study of conventional colonoscopy and pan-colonic narrow-band imaging system in the detection of neoplastic colonic polyps: a randomized, controlled trial. Journal of Gastroenterology. 2008; 43: 45-50.

22. Chan D.K.H., Wong R.K.M., Yeoh K.G., Tan K.K.: Accredited residents perform colonoscopy to the same high standards as consultants. Surg Endosc. 2018 Mar; 32 (3): 1377-1381.

23. Williams M.R., Crossett J.R., Cleveland E.M.: et al Equivalence in colonoscopy results between gastroenterologists and general surgery residents following an endoscopy simulation curriculum. J Surg Educ. 2015 Jul-Aug; 72 (4): 654-657.

\begin{tabular}{llll}
\hline Word count: $2720 \quad$ Page count: 7 & Tables: 5 & Figures: - & References: 23
\end{tabular}

DOI: $\quad 10.5604 / 01.3001 .0012 .0755 \quad$ Table of content: https://ppch.pl/issue/11379

Copyright: Copyright @ 2018 Fundacja Polski Przegląd Chirurgiczny. Published by Index Copernicus Sp. z o. o. All rights reserved.

Competing interests: The authors declare that they have no competing interests.

The content of the journal „Polish Journal of Surgery” is circulated on the basis

- of the Open Access which means free and limitless access to scientific data.

Corresponding author:

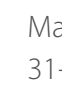

Cite this article as:

This material is available under the Creative Commons - Attribution 4.0 GB. The full terms of this license are available on: http://creativecommons.org/licenses/by-nc-sa/4.0/legalcode

it effective in the hands of a general surgery resident?; Pol Przegl Chir 2018: 90 (5): 6-12 
